\title{
Kontribusi Usahatani Kakao terhadap Pendapatan Rumah Tangga Petani di Desa Pangsan, Kecamatan Petang, Kabupaten Badung
}

\author{
ELTA DINA PARTIWI, I WAYAN BUDIASA, \\ I WAYAN WIDYANTARA
}

\author{
Program Studi Agribisnis, Fakultas Pertanian, Universitas Udayana \\ J1. PB. Sudirman Denpasar 80323 \\ Email: elta_dina@yahoo.com \\ wba.agr@unud.ac.id
}

\author{
Abstract \\ Contribution of Cocoa Farming to Farmers Household Income \\ in Pangsan Village, Petang District, Badung Regency
}

The study aims to determine the sources of cocoa farmers' income, and the large contribution of cocoa farming to the income of the farmers' households in Pangsan Village, as well as to find out the physical management practices and postharvest handling applied by the cocoa farmers. The technique of determining the sample was by using proportional random sampling and the sample was taken randomly to select the sample by lottery method with the number of samples of 34 cocoa farmers. The data collection was conducted from early February to the end of February 2017. The study used farming analysis to calculate net income and total household income of cocoa farmers during 2016. The results showed that cocoa farming has the highest contribution of $70.10 \%$ of the total household income of farmers amounting to Rp. $85,954,990.80$ / year with an average income of Rp. 60,252,258 / year. The physical management practices of cocoa farming applied by cocoa farmers in Pangsan Village are in accordance with the physical management practices in the cocoa Good Agricultural Practices (GAP) guidelines, and it is known that farmers did not apply Good Handling Practices (GHP) to postharvest handling.

Keywords: cocoa, household income, contribution, good agriculture practice

\section{Pendahuluan}

\subsection{Latar Belakang}

Perkebunan merupakan subsektor yang memiliki jumlah rumah tangga usaha pertanian yang melakukan pengolahan hasil pertanian terbanyak di Provinsi Bali. Jumlah rumah tangga usaha pertanian yang melakukan pengolahan hasil pertanian pada subsektor perkebunan di tahun 2013 tercatat sebanyak 8.624 rumah tangga (Antara, 2013). Salah satu tanaman perkebunan yang banyak dikembangkan adalah, komoditas kakao yang merupakan komoditi unggulan di bidang perkebunan, kakao memiliki potensi dan peluang untuk dikembangkan dalam usaha meningkatkan pendapatan petani. Perkebunan kakao menyumbang banyak pendapatan bagi pemerintah dan petani kakao (Distanbunhut, Badung 2013). 
Kakao merupakan salah satu komoditi perkebunan di Bali yang memberikan sumbangan terbesar setelah komoditi perkebunan unggulan lainnya. Sumbangan kakao terhadap devisa diketahui sebesar 709.968,98 dolar AS. Komoditas kakao hasil perkebunan rakyat di Bali mulai memasuki pasar ekspor 4.703 ton seharga 709.968,98 dolar AS, dengan tujuan utama pasaran Amerika Serikat (Teneng, 2013).

Kabupaten Badung merupakan salah satu Kabupaten yang memiliki potensi yang sangat potensial untuk mengembangkan tanaman kakao. Kabupaten Badung pengembangan tanaman kakao dilakukan di tiga Kecamatan yaitu di Kecamatan Mengwi, Abiansemal dan Petang, dengan sentra luas areal tanam kakao terluas, tingkat produksi dan produktivitas yang tinggi di kecamatan Abiansemal dan disusul oleh kecamatan Petang, dan kemudian Mengwi. Seperti yang terlihat pada tabel 1. berikut .

Tabel 1.

Luas Areal. Produksi, dan Produktivitas Tanaman Kakao Kabupaten Badung, 2015

\begin{tabular}{cccc}
\hline Kecamatan & $\begin{array}{c}\text { Luas Areal } \\
\text { (ha) }\end{array}$ & $\begin{array}{c}\text { Produksi } \\
\text { (Ton) }\end{array}$ & $\begin{array}{c}\text { Produktivitas } \\
(\mathrm{Kg} / \mathrm{ha} / \mathrm{th})\end{array}$ \\
\hline Mengwi & 56 & 19,38 & 383 \\
Abiansemal & 373 & 13,84 & 656 \\
Petang & 173 & 23,77 & 434 \\
\hline
\end{tabular}

Sumber: Dinas Perkebunan Provinsi Bali, 2015

Salah satu desa yang mengembangkan tanaman kakao adalah Desa Pangsan, Kecamatan Petang. Desa Pangsan merupakan salah satu desa agrowisata yang memiliki kekayaan sumber daya alam. Kekayaan sumber daya alam yang dimiliki oleh Desa Pangsan telah dioptimalkan oleh warganya dengan cara memaksimalkan pengembangan komoditi yang terdapat di daerah tersebut. Salah satu sumber komoditi yang dominan diandalkan oleh warga Desa Pangsan adalah kakao (Desa Pangsan, 2016).

Usaha pembudidayaan kakao di Desa Pangsan dilakukan secara berkelanjutan, sehingga usahatani kakao ini dijadikan sebagai salah satu sumber pendapatan rumah tangga petani. Kurangnya kelembagaan pemasaran yang ada menjadi salah satu kendala petani untuk memasarkan hasil produksinya, dan secara langsung hal tersebut mempengaruhi tingkat pendapatan petani kakao. Meski mengalami kendala dalam segi kelembagaan pemasarannya, petani kakao tetap mempertahankan untuk membudidayakan tanaman kakao secara berkelanjutan dan menjadi sebagai salah satu sumber pendapatan petani. Pendapatan yang diperoleh petani dari usahatani kakao tentunya memberikan kontribusi terhadap pendapatan rumah tangga petani di Desa Pangsan, namun besar kontribusi dari usahatani kakao belum diketahui terhadap pendapatan rumah tangga petani. Berdasarkan pemaparan di atas maka 
mendorong penulis untuk mengadakan penelitian mengenai besarnya kontribusi usahatani kakao terhadap pendapatan rumah tangga petani kakao di Desa Pangsan, Kecamatan Petang, Kabupaten Badung.

\subsection{Tujuan Penelitian}

Tujuan dari penelitian ini adalah untuk mengetahui hal-hal sebagai berikut

1. Untuk mengetahui besar kontribusi usahatani kakao terhadap pendapatan rumah tangga petani kakao di Desa Pangsan, Kecamatan Petang, Kabupaten Badung.

2. Untuk mengetahui praktek manajemen fisik usahatani dan penanganan pasca panen kakao di Desa Pangsan.

\section{Metode Penelitian}

\subsection{Lokasi dan Waktu Penelitian}

Penelitian dilakukan di Desa Pangsan, Kecamatan Petang, Kabupaten Badung dan dilaksanakan pada awal bulan Februari sampai dengan akhir bulan Februari 2017. Pemilihan lokasi dilakukan dengan metode purposive (sengaja) yang berdasarkan bahwa Desa Pangsan merupakan Desa di Kecamatan Petang yang memiliki jumlah KK petani terbanyak yang mengusahakan tanaman kakao yaitu 586 KK (UPTD Kecamatan Petang, 2016).

\subsection{Metode Pengumpulan Data dan Variabel Penelitian}

Pengumpulan data yang digunakan pada penelitian ini dengan melakukan survey usahatani. Survey usahatani dilakukan dengan mengedarkan kuisioner, yang berisikan daftar pertanyaan kepada responden yang sudah dipersiapkan sebelumnya. Variabel-variabel yang dianalisis pada penelitian ini adalah sumber pendapatan masing-masing rumah tangga petani yaitu pendapatan usahatani kakao pendapatan usahatani lainnya (pisang dan kelapa) serta pendapatan non usahatani dalam tahun 2016. Pendapatan usahatani kakao dan pendapatan usahatani lainnya dianalisis secara kuantitatif dengan menggunakan analisis usahatani. Praktik manajemen fisik yang diterapkan oleh petani kakao dijelaskan dengan deskriptif kualitatif yang berpedoman pada GAP kakao.

\subsection{Populasi dan Sampel}

Populasi adalah wilayah yang terdiri atas obyek atau subyek yang mempunyai kualitas dan karakteristik tertentu yang ditetapkan oleh peneliti untuk dipelajari dan kemudian ditarik kesimpulannya (Sugiyono, 2012). Populasi dalam penelitian ini adalah sebanyak 138 petani kakao yang berasal dari tiga Subak Abian di Desa Pangsan yaitu; Subak Abian Dhana Asih, Subak Abian Kembang Sari, dan Subak Abian Nata Nugraha.

Sampel adalah bagian dari jumlah dan karakteristik yang dimiliki oleh populasi tersebut (Sugiyono, 2012). Metode yang digunakan dalam penentuan jumlah sampel ini adalah dengan rumus Slovin (Setiawan, 2007). 


$$
\mathrm{n}=\frac{\mathrm{N}}{1+\mathrm{Na}^{2}}
$$

Keterangan :

$\mathrm{n} \quad=$ jumlah sampel

$\mathrm{N} \quad=$ jumlah populasi

$\mathrm{e} \quad=$ batas toleransi kesalahan (error tolerance)

Penelitian ini menggunakan teori Slovin dengan batas toleransi kesalahan sebesar $15 \%$, sehingga jumlah sampel yang diperoleh berdasarkan hasil perhitungan sebanyak 34 petani dari 138 petani kakao dari tiga Subak Abian di Desa Pangsan. Pemilihan sampel dilakukan secara acak dengan undian.

\subsection{Metode Analisis}

Analisis yang digunakan untuk mengetahui total pendapatan rumah tangga dari sumber-sumber pendapatan petani adalah sebagai berikut:

$$
\pi_{\mathrm{rt}}=\pi_{\mathrm{uk}}+\pi_{\mathrm{ul}}+\pi_{\mathrm{nu}}
$$

Keterangan:

$\pi_{\mathrm{rt}} \quad$ : Pendapatan rumah tangga

$\pi_{\mathrm{uk}} \quad$ : Pendapatan usahatani kakao $(\mathrm{Rp} / \mathrm{th})$

$\pi_{\mathrm{ul}} \quad$ : Pendapatan usahatani lainnya $(\mathrm{Rp} / \mathrm{th})$

$\pi_{\mathrm{nu}} \quad$ : Pendapatan non usahatani $(\mathrm{Rp} / \mathrm{th})$

Menurut Soekartawi (2002), analisis yang digunakan untuk mengetahui pendapatan usahatani, meliputi pendapatan usahatani kakao adalah sebagai berikut:

$$
\pi_{\mathrm{uk}}=\mathrm{TR}-\mathrm{TC}
$$

Keterangan:

$\pi_{\mathrm{uk}}:$ Pendapatan usahatani kakao (Rp/th)

TR : Total penerimaan (total revenue) kakao yang diperoleh tahun 2016 (Rp/th)

TC : Total Biaya (total cost) kakao tahun 2016 (Rp/th)

Analisis yang digunakan untuk mengetahui pendapatan usahatani lainnya (pisang dan kelapa) adalah sebagai berikut:

$$
\pi_{\mathrm{ul}}=\mathrm{TR}-\mathrm{TC}
$$

Keterangan:

$\pi_{\mathrm{ul}}$ : Pendaapatan usahatani lainnya dalam satu tahun $2016(\mathrm{Rp} / \mathrm{th})$

TR : Total revenue atau total penerimaan usahatani lainnya yang diperoleh tahun 2016 (Rp/th)

TC : Total cost atau total biaya usahatani lainnya tahun $2016(\mathrm{Rp} / \mathrm{th})$ 
Analisis yang digunakan untuk mengetahui pendapatan yang bersumber dari non usahatani adalah sebagai berikut:

$$
\pi_{\mathrm{nu}}=\pi_{\mathrm{tg}}+\pi_{\mathrm{bb}}+\pi_{\mathrm{pg}}
$$

Keterangan:

$\pi_{\mathrm{nu}}:$ Pendapatan non usahatani/th

$\pi_{\mathrm{bb}}:$ Pendapatan buruh bangunan/th

$\pi_{\mathrm{pd}}:$ Pendapatan pedagang/th

$\pi_{\mathrm{pg}} \quad$ : Pendapatan pegawai/th

Kontribusi pendapatan usahatani adalah pendapatan yang diterima dari usahatani dibagi dengan pendapatan keluarga dan dikalikan 100\%, sehingga dapat diketahui seberapa besar kontribusi usahatani terhadap pendapatan keluarga (Tohir, 1991)

$$
K u k=\frac{\pi u k(R p)}{\pi r t(R p)} \times 100
$$

Keterangan:

$\mathrm{K}_{\mathrm{uk}}$ : Kontribusi usahatani kakao $(100 \%)$

$\pi_{\mathrm{uk}}$ : Pendapatan usahatani kakao $(\mathrm{Rp})$

$\pi_{\mathrm{rt}}:$ Pendapatan rumah tangga $(\mathrm{Rp})$

Pada praktek manajemen fisik usahatani kakao dan penanganan pascapanen kakao di Desa Pangsan Kecamatan Petang Kabupaten Badung akan dianalisis dengan menggunakan deskriptif kualitatif yang berpedoman pada Good Agriculture Practice On Cocoa (GAP kakao) dan Good Handling Practice On Cocoa (GHP kakao).

\section{Hasil dan Pembahasan}

\subsection{Pendapatan Usahatani Kakao}

Usahatani kakao di Desa Pangsan merupakan salah satu sumber pendapatan rumah tangga petani. Usahatani kakao merupakan salah satu sumber pendapatan, dan memberikan kontribusi terhadap pendapatan rumah tangga petani. Pendapatan usahatani kakao dihitung pada tahun 2016, dengan menghitung penerimaan petani tahun 2016. Tanaman kakao yang dianalisis berumur 15 tahun dengan siklus produksi pada tahun 2016. Biaya yang dikeluarkan petani terdiri atas dua komponen yaitu biaya tunai dan biaya yang diperhitungkan. Biaya tunai terdiri dari biaya tetap dan biaya variabel. Biaya tetap meliputi biaya pajak, dan biya variabel meliputi biaya pupuk pupuk organik, pupuk kandang, biaya TKLK, dan obat-obatan. Pada biaya yang diperhitungkan meliputi biaya tetap seperti penyusutan alat-alat perkebunan, biaya variabel meliputi biaya TKDK. Hasil analisis pendapatan usahatani kakao tahun 2016 per luas garapan dapat dilihat pada tabel 2. 
Tabel 2.

Rata-rata pendapatan Usahatani Kakao Per Luas Garapan, Tahun 2016

\begin{tabular}{|c|c|c|c|}
\hline Ket & Komponen Biaya & $\begin{array}{l}\text { Nilai }(\mathrm{Rp} / \text { luas } \\
\text { garapan/ th) }\end{array}$ & $\begin{array}{l}\text { Persentase } \\
\quad(\%)\end{array}$ \\
\hline A. & Rata-rata Penerimaan & 70.013 .051 & - \\
\hline \multicolumn{4}{|c|}{ Biaya Tunai } \\
\hline B. & \multicolumn{3}{|l|}{ Biaya Tetap } \\
\hline & a. Pajak & 15.529 & 0,16 \\
\hline \multicolumn{2}{|c|}{ Subtotal } & 15.529 & 0,16 \\
\hline \multicolumn{4}{|c|}{ Biaya Variabel } \\
\hline & a. Pupuk Organik & $427.941,18$ & 4,38 \\
\hline & b. TKLK & $1.435 .036,76$ & 14.70 \\
\hline & c. Obat-obatan & $50.000,00$ & 0,51 \\
\hline & b. Pupuk Kandang & $120.852,94$ & 1,24 \\
\hline \multicolumn{2}{|c|}{ Subtotal } & $2.033 .830,88$ & 20,84 \\
\hline \multicolumn{2}{|c|}{ Total Biaya Tunai } & $2.049 .360,29$ & 21,00 \\
\hline \multicolumn{4}{|c|}{ Biaya yang diperhitungkan } \\
\hline \multirow[t]{2}{*}{ C. } & Biaya Tetap & & \\
\hline & a. Penyusutan Alat Perkebunan & $371.524,51$ & 3,81 \\
\hline \multicolumn{2}{|c|}{ Subtotal } & $371.524,51$ & 3,81 \\
\hline \multicolumn{4}{|c|}{ Biaya Variabel } \\
\hline & a. TKDK & 7.339 .908 & 75,20 \\
\hline \multicolumn{2}{|c|}{ Subtotal } & 7.339 .908 & 75,20 \\
\hline \multicolumn{2}{|c|}{ Total Biaya Diperhitungkan } & $7.711 .432,60$ & 79,00 \\
\hline \multicolumn{2}{|c|}{ D. Total Biaya $(B+C)$} & $9.760 .792,89$ & 100 \\
\hline E. & $\begin{array}{l}\text { Pendapatan Atas Biaya Total (A- } \\
\text { D) }\end{array}$ & 60.252 .258 & - \\
\hline
\end{tabular}

Sumber: Data primer diolah (2017)

Berdasarkan tabel 2, diketahui bahwa rata-rata pendapatan usahatani kakao tahun 2016 adalah Rp 60.252.258/th. Biaya yang paling besar dikeluarkan petani adalah biaya yang diperhitungkan, pada biaya TKDK sebesar Rp 7.339.908 dengan persentase $75,20 \%$. Hal ini dikarenakan petani kakao lebih menekan jumlah biaya input produksi pada tenaga kerja, petani menggunakan lebih banyak tenaga kerja dalam keluarga saat proses produksi dikarenakan sebagian besar petani kakao di Desa Pangsan masih tergolong usia produktif, dan tidak semua proses produksi membutuhkan TKLK.

\subsection{Pendapatan usahatani lainnya}

Petani kakao di Desa Pangsan tidak hanya mengusahakan usahatani kakao sebagai sumber pendapatan. Sebagian besar petani juga mengusahakan usahatani 
lainnya seperti usahatani pisang dan kelapa untuk menambah pendapatan. Rata-rata pendapatan usahatani lainnya per luas garapan tahun 2016 dapat dilihat pada tabel 3.

Tabel 3.

Rata-rata Pendapatan Usahatani Lainnya Per Luas Garapan, Tahun 2016

\begin{tabular}{cccc}
\hline Ket & Komponen Biaya & $\begin{array}{c}\text { Nilai (Rp/ Luas } \\
\text { Garapan/ th) }\end{array}$ & Persentase (\%) \\
\hline A. & Rata-rata Penerimaan & $3.723 .235,29$ & -
\end{tabular}

Biaya Tunai

B. Biaya Tetap
a. Pajak
31.059

Subtotal

Biaya Variabel

$\begin{array}{lll}\text { a. TKLK } & 67.058,82 & 6,13\end{array}$

b. Pupuk Kandang $\quad 226.779,41 \quad 20,74$

Subtotal

$293.838,24 \quad 26,88$

\begin{tabular}{lll}
\hline Total Biaya Tunai & $324.897,06$ & 29,72 \\
\hline
\end{tabular}

C. Biaya Tetap

Biaya Diperhitungkan

a. Penyusutan Alat Perkebunan $\quad 115.817 \quad 10,59$

Subtotal

$115.817 \quad 10,59$

Biaya Variabel

a. TKDK

$652.515,44$

59,69

Subtotal

$652.515,44$

59,69

\begin{tabular}{llrr}
\multicolumn{2}{l}{ Total Biaya yang Diperhitungkan } & $768.332,43$ & 70,28 \\
\hline D. & Total Biaya (B+C) & $1.093 .229,49$ & 100 \\
\hline E. $\quad$ Pendapatan Ut Pisang dan Kelapa (A-D) & $2.630 .005,80$ & - &
\end{tabular}

Sumber: Data primer diolah (2017)

Berdasarkan tabel 3, diketahui bahwa rata-rata pendapatan dari usahatani pisang dan kelapa adalah Rp 2.630.005,80, dengan biaya yang paling besar dikeluarkan oleh petani adalah biaya yang diperhitungkan, pada biaya TKDK yaitu dengan rata-rata biaya $\operatorname{Rp} 652.515,44$ dan persentase sebesar 59,69\%.

\subsection{Pendapatan Non Usahatani}

Pendapatan petani umunya tidak hanya terdiri dari satu sumber pendapatan, untuk memenuhi kebutuhan. Umumnya, untuk menambah pendapatan rumah tangga, petani memiliki pekerjaan lainya diluar dari berusahatani. Petani kakao di Desa Pangsan dominan memiliki sumber pendapatan yang berasal dari luar usahatani. Pendapatan non usahatani petani kakao di Desa Pangsan bersumber dari Pedagang, Buruh Bangunan, dan Pegawai Negeri Sipil. Adapun rata-rata pendapatan dari non usahatani dapat dilihat pada tabel 4 . 
Tabel 4.

Rata-rata Pendapatan Non Usahatani Per Tahun

\begin{tabular}{ccccc}
\hline \multirow{2}{*}{ No } & \multirow{2}{*}{ Pekerjaan } & \multirow{2}{*}{ Jumlah (orang) } & \multicolumn{2}{c}{ Rata-rata Pendapatan } \\
\cline { 3 - 5 } & & $\mathrm{Rp}$ & Persentase $(\%)$ \\
\hline 1 & Pedagang & 11 & 8.018 .182 & 11,58 \\
2 & Pegawai Negeri Sipil & 7 & 37.200 .000 & 53,74 \\
3 & Buruh Bangunan & 6 & 24.000 .000 & 34,67 \\
\hline & Jumlah & 24 & 69.218 .182 & 100 \\
\hline
\end{tabular}

Sumber: Data primer diolah (2017)

Berdasarkan tabel 4, diketahui bahwa jumlah pendapatan dari non usahatani adalah Rp 69.218.182/th dengan rata-rata pendapatan Rp 23.072.727/th. Rata-rata pendapatan terbesar adalah Pegawai Negeri Sipil dari dua pendapatan non usahatani lainya dengan rata-rata $\mathrm{Rp} 37.200 .000 /$ th dan persentase $53,74 \%$.

\subsection{Kontribusi Usahatani Kakao terhadap Pendapatan Rumah Tangga Petani}

Terdapat tiga sumber pendapatan petani kakao di Desa Pangsan yaitu usahatani kakao, usahatani lainnya yang meliputi usahatani pisang, usahatani kelapa, dan ternak sedangkan pada non usahatani terdiri dari pedagang, buruh bangunan, dan PNS. Ketiga sumber pendapatan tersebut memiliki kontribusi terhadap pendapatan rumah tangga petani. Untuk lebih jelasnya dapat dilihat pada tabel 5.

Tabel 5

Total Pendapatan Rumah Tangga Petani pada Usahatani Kakao, Usahatani Lainnya, dan Non Usahatani di Desa Pangsan, Tahun 2016

\begin{tabular}{clcc}
\hline \multirow{2}{*}{ No } & Sumber pendapatan & Rata-rata pendapatan (Rp) & Persentase (\%) \\
& & 60.252 .258 & 70,10 \\
2 & Kakao & 2.630 .006 & 3,06 \\
3 & UT Lainnya & 23.072 .727 & 26,84 \\
\hline & Non Usahatani & 85.954 .990 & 100
\end{tabular}

Sumber: Data primer diolah (2017)

Berdasarkan tabel 5, diketahui bahwa sumber pendapatan petani terbesar bersumber dari usahatani kakao dengan rata-rata pendapatan Rp 60. 252.258 dengan persentase $70,10 \%$.

\subsection{Manajemen Fisik dan Penanganan Pasca Panen Kakao}

Good Agriculture Practice kakao (GAP kakao) merupakan pedoman teknis dalam manejemen fisik proses produksi kakao dan Good Handling Practice kakao (GHP kakao) merupakan pedoman yang dianjurkan dalam penanganan pasca panen kakao. Kedua pedoman tersebut dianjurkan, agar usahatani yang diusahakan dapat berkelanjutan, dan memiliki kualitas yang bermutu. Pada manajemen fisik dalam 
pedoman GAP kakao terdapat lima manajemen kegiatan yaitu, sistem tanam, manajemen lahan meliputi kesesuaian lahan dan pemupukan, manajemen irigasi, pengendalian hama dan penyaikt tanaman, serta panen. Pada pedoman GHP kakao terdiri atas penanganan pasca panen berupa tahap fermentasi.

Manajemen fisik yang diterapkan petani di Desa Pangsan meliputi sistem tanam, yaitu sistem tanam tumpangsari dan merupakan sistem tanam yang dianjurkan dalam pedoman GAP kakao. Manajemen lahan berupa kesesusian lahan Desa Pangsan tergolong kedalam golongan lahan $\mathrm{S}_{2}$ atau sesuai (moderately suitable) berdasarkan perbandingan topografi desa dengan kriteria kesesuain lahan pada GAP kakao. Pada manajemen pemupukan petani kakao di Desa Pangsan melakukan pemupukan sebanyak dua kali dalam setahun. Pemupukan dilakukan dengan membuat lubang melingkar di sekitar tanaman kakao dengan kedalaman lubang ratarata dua s.d. tiga $\mathrm{cm}$ secara teknis pemupukan yang dilakukan petani sudah sesuai dengan pedoman yang dianjurkan pada GAP kakao. Pengandalian hama dan penyakit dilakukan oleh petani dengan menggunakan pestisida yang telah terdaftar pada Kementrian Pertanian. Pemakaian pestisida oleh petani di sesuaikan dengan kebutuhan pemakaian dan dosis obat. Pada pedoman GAP kakao, teknis pengendalian hama dengan menggunakan pestisida yang diterapkan petani sudah seusai dengan menggunakan pestisida yang aman dan terdaftar serta memperhatikan dosis pemakaian obat. Pada pedoman GAP kakao, manajemen irigasi berupa penyiraman yang tumbuh dengan kondisi tanah yang baik, tidak memerlukan banyak air. Air yang berlebihan akan menyebabkan kondisi tanah menjadi sangat lembab. Penyiraman dilakukan pada tanaman muda, terutama tanaman yang tidak memiliki pohon pelindung. Petani kakao di Desa Pangsan tidak melakukan penyiraman pada tanaman kakao dikarenakan kondisi dan lahan di Desa Pangsan tergolong baik dan sesuai dalam pembudidayaan kakao.

Pada tahap pemanenan dalam pedoman GAP panen idealnya dilakukan seminggu sampai dua minggu sekali. Pemetikan buah dilakukan dengan menggunakan alat bantu. Buah yang telah terkumpul di sortir dengan memisahkan buah yang busuk. Pemecahan buah dilakukan dengan membenturkan buah kakao satu dengan lainnya atau dengan alat berupa pemukul kayu. Pada tahap akhir biji kakao basah kemudian dijemur selama tiga s.d. lima hari sampai menjadi biji kering. Petani kakao di Desa Pangsan melakukan pemanenan seminggu sekali dengan memetik buah kakao menggunakan gunting pemetik dan lansung mensortir buah yang busuk sebelum dikumpulkan. Petani melakukan pemecahan buah dengan membenturkan buah kakao satu dengan buah kakao lainya. Buah kakao kemudian di keringkan selama tiga sampai lima hari. Berdasarkan tahap pemanenan yang dilakukan, petani sudah menerapkan tahap panen yang dianjurkan pda pedomn GAP.

Manajemen fisik yang diterapkan petani kakao di Desa Pangsan sudah tergolong baik dan sesuai dengan manajemen fisik yang dianjurkan pada pedoman GAP. Petani kakao di desa Pangsan diketahui tidak melakukan GHP pada penganan pasca panen berupa fermentasi. 


\section{Simpulan dan Saran}

\subsection{Simpulan}

Sumber pendapatan rumah tangga petani di Desa Pangsan terdiri atas tiga sumber pendapatan yaitu usahatani kakao, usahatani lainnya, dan pendapatan non usahatani. Usahatani kakao merupakan sumber pendapatan tertinggi dengan rata-rata pendapatan Rp 60.252.258/th (70,10\%) dari total pendapatan rumah tangga Rp 85.954.990,80 dari sumber pendapatan lainnya. Manajemen fisik yang diterapkan petani kakao di Desa Pangsan sudah tergolong baik dan sesuai dengan manajemen fisik yang dianjurkan pada pedoman GAP, namun petani sampel tidak menerapkan GHP pada kegiatan pascapanen.

\subsection{Saran}

Saran yang dpat diberikan pada penelitian ini (1) Petani tetap dapat mempertahankan dan meningkatkan manejemn fisik yang telah diterapkan yang telah sesuai dengan pedoman GAP. Petani diharapkan dapat menerapkan GHP pada kegiatan usahataninya yaitu pada penanganan pascapanen secara teknologi seperti fermentasi biji dan, (2) Pemerintah diharapkan tetap memberikan bantuan input produksi secara kontinyu, guna membantu petani dalam menekan biaya selama proses produksi, memberikan penyuluhan mengenai GHP dan pentingnya melakukan penanganan pascapanen kakao berupa fermentasi biji. Peran pemerintah diperlukan untuk membantu pemasaran produksi petani dengan membentuk lembaga pemasaran di Desa Pangsan untuk mewadahi produksi kakao, sehingga petani memiliki referensi untuk memasarkan produksinya.

\section{Ucapan Terimakasih}

Ucapan terimakasih penulis tujukan kepada semua pihak yang telah membantu penulis dalam melaksanakan penelitian hingga karya ilmiah ini bisa dipublikasikan dalam e-jurnal.

\section{Daftar Pustaka}

Antara Semadi. 2013. Selayang Pandang Pertanian di Bali. .http://staff.unud.ac.id Diunduh pada 28 November 2016

Disbun Bali. 2015. Luas Areal. Produksi dan Produktivitas Tanaman Kakao 2015. Bali

Distanbunhut. 2013. Laporan Tahunan Kegiatan Penanggulangan Organisme Pengganggu Tanaman (OPT) Perkebunan dan Kehutanan Secara Organik di Kabupaten Badung Tahun 2013. Kabupaten Badung. Diakses pada 28 November 2016

Desa Pangsan. 2016. Keadaan Perkebunan Kakao. http://pangsanbali.blogspot.com/. Diunduh pada 30 Januari 2017

Kaslan. A Tohir. 1991. Seuntai Pengetahuan Usaha Tani Indonesia. PT. Rineka Cipta. Jakarta. 
Sugiyono. 2012. Metode Penelitian Kuantitatif Kualitatif Dan $R \& B$. ALFABETA.Bandung

Setiawan, Nugraha. 2007. Penentuan Ukuran Sampel Memakai Rumus Slovin dan Tabel Krejcie Morgan: Telaah Konsep dan Aplikasinya. http://pustaka.unpad.ac.id Diunduh pada 25 November 2016

Soekartawi. 2002. Analisis Usaha Tani. UI - Press. Jakarta

Teneng. 2013. dalam Jurnal Haji.(berita online).Tiga Komoditas Perkebunan Bali Tembus Ekspor. http://www.republika.co.id. Diunduh pada 28 November 2016

UPDT Kecamatan Petang. 2016. Luas Areal, dan Produksi Komoditi Perkebunan Kakao Triwulan Dua Tahun 2016. 